STUDI

FRANCESI

\section{Studi Francesi}

Rivista quadrimestrale fondata da Franco Simone

179 (LX | II) | 2016

Varia

\title{
Régis Lefort, Étude sur la poésie contemporaine. Des affleurements du réel à une philosophie du vivre
}

\section{Fabio Scotto}

\section{(2) OpenEdition}

1 Journals

\section{Edizione digitale}

URL: http://journals.openedition.org/studifrancesi/4472

DOI: $10.4000 /$ studifrancesi.4472

ISSN: 2421-5856

\section{Editore}

Rosenberg \& Sellier

\section{Edizione cartacea}

Data di pubblicazione: 1 settembre 2016

Paginazione: 364-365

ISSN: 0039-2944

\section{Notizia bibliografica digitale}

Fabio Scotto, «Régis Lefort, Étude sur la poésie contemporaine. Des affleurements du réel à une philosophie du vivre », Studi Francesi [Online], 179 (LX | II) | 2016, online dal 01 septembre 2016, consultato il 18 septembre 2020. URL : http://journals.openedition.org/studifrancesi/4472 ; DOI : https://doi.org/10.4000/studifrancesi.4472

Questo documento è stato generato automaticamente il 18 settembre 2020.

\section{(c)}

Studi Francesi è distribuita con Licenza Creative Commons Attribuzione - Non commerciale - Non opere derivate 4.0 Internazionale. 


\title{
Régis Lefort, Étude sur la poésie contemporaine. Des affleurements du réel à une philosophie du vivre
}

\author{
Fabio Scotto
}

\section{NOTIZIA}

RÉGIS LEFORT, Étude sur la poésie contemporaine. Des affleurements du réel à une philosophie du vivre, Paris, Classiques Garnier, 2014, «Études de littérature des $\mathrm{xx}^{\mathrm{e}}$ et $\mathrm{XxI}^{\mathrm{e}}$ siècles» 45, $379 \mathrm{pp}$.

1 Lo studio di Régis Lefort si propone di scandagliare il complesso paesaggio della poesia francese contemporanea attraverso un'interazione di approcci che vanno dalla poetica alla critica, dalla riflessione filosofica alle pratiche di meditazione orientali, non a caso il riferimento più costante è l'opera di François Jullien, nella quale la filosofia incontra la poesia attraverso una riflessione sulle dinamiche interstiziali dell'evento evocato, quindi sull'infra, sui silenzi e i vuoti, ovvero sull'intermittenza vocale e testuale.

2 Nell'«Introduction» (pp. 11-31), l'A. ben illustra motivi e ragioni all'origine della sua indagine identificando nell'«affleurement du réel» il luogo di coagulazione della presenza che preesiste a ogni elaborazione concettuale e linguistica e che situa la poesia fra mimesi e immaginazione. Alla luce di questa dialettica dell'adesione e dell'astrazione, Lefort convoca varie figure e teorizzazioni, dal culto dell'immagine e dell'immaginazione di Pierre Reverdy e Salah Stétié alla «ressemblance sans la ressemblance» di Bernard Vargaftig, dal «réel comme transparence» di Jacques Ancet all'opposizione «réel/réalité» di Philippe Forest, per in fondo constatarne l'insufficienza e l'incapacità di vera definizione (le chiama, non a caso, «indéfinitions»). Per questo cerca un appiglio meno malfermo nella filosofia, ad esempio in Clément Rosset, che vede nella poesia il tentativo di sottrarsi all'idealizzazione del reale attraverso il superamento del rischio insito nella nozione d'attesa, cara anche a 
Barthes, mediante l'affioramento del «caractère vibratoire du poème», e soprattutto in François Jullien, che identifica nelle faglie del linguaggio, nell'interstizio e nell'intervallo il luogo dell'apparizione e il meccanismo stesso di funzionamento della poesia; nozione non sistematica che oppone al sistema il «diastème», ovvero ciò che crea nessi non per complementarità, ma "par écart ouvrant de l'entre entre les éléments en les mettant en tension».

Diviso in cinque parti, intitolate rispettivamente «L'Espace de l'inconscient» (pp. 35-97), con capitoli su Julien Gracq, Henri Bauchau et Pierre Jean Jouve, «Un Théâtre de langue» (pp. 101-156), che verte su Pascal Commère, Arno Calleja e Jean Tortel, «Silence et figure(s) du sujet» (pp. 159-215), dedicata a Roger Kowalski, Bernard Vargaftig e Gérard Titus-Carmel, «Le Corps pris dans le poème» (pp. 219-273), su Antoine Emaz, Jean-Louis Giovannoni, Lorand Gaspar, «Un Art du peu» (pp. 275-337), incentrata su Christian Hubin, François Jacqmin e Anne-Marie Albiach, l'opera si segnala per il criterio singolare e del tutto non scontato di scelta, che associa figure di primo piano già ben storicizzate come, ad esempio, Gracq, Bauchau, Jouve, Tortel e Gaspar, ad altre meno note al pubblico e appartenenti all'«extrême contemporain» della poesia attuale.

4 L'articolazione in parti corrisponde a quella che nell'Introduzione l'A. chiama, sempre nel solco della nozione diastemica di Jullien, un'axiologia che nella successione dei rispettivi titoli delinea un paradigma che va dal corpo all'inconscio, dal teatro della lingua al silenzio e al poco. Se la poesia attinge principalmente all'inconscio, come da sempre sostenuto da Yves Bonnefoy, riferimento critico in queste pagine ricorrente, essa poi necessita di uno spazio teatrale nel quale dispiegarsi come linguaggio, un linguaggio che si serve dell'alternanza di parola e silenzio, preludio a un'interazione fra il corpo e il mondo, e che si riduce, nelle sue forme ellittiche più estreme, a una contrazione verbale in un'espressione frammentaria e sbriciolata, a suo modo pulviscolare, come a suo tempo già preconizzata dalla poétique en archipel di René Char.

5 Il fatto è che, come Lefort sostiene nella «Conclusion» (pp. 339-353), la poesia implica «le mouvement de la pensée vers l'impensable», un'impensabile che si fa reale per affioramenti in uno spazio-tempo fortemente soggettivizzato dall'emozione e che ha un tratto di singolarità critica nell'identificazione di un'analogia profonda della poesia con la danza, la quale, benché già evocata a suo tempo da Rimbaud, trova qui una sua piena rispondenza nel movimento parallelo di corpo e testo: «Le poète comme le danseur ne sont plus alors que sujets errants. Tous deux entretiennent une relation de dépendance avec un acte sans futur ni passé, hérité d'un arrière-pays. Tous deux sont en quête de l'innocence du premier acte».

6 Corredano il testo una «Bibliographie» (pp. 355-368) e un «Index des noms propres» (pp. 367-374). 